\title{
Megalopolis unbound: Knowledge collaboration and functional polycentricity within and beyond the Yangtze River Delta Region in China, 2014
}

Urban Studies

$1-17$

(c) Urban Studies Journal Limited 2016 (c) (1) (8)

Reprints and permissions: sagepub.co.uk/journalsPermissions.nav DOI: |0.1 I77/00420980|665697|

usj.sagepub.com

\section{Yingcheng Li}

Bartlett School of Planning, University College London, UK

\section{Nicholas Phelps}

Bartlett School of Planning, University College London, UK

\begin{abstract}
Recent work on world city networks, urban polycentricity and megapolitan urban forms share an interest in the economic functionality of inter-city linkages. The intersection of these bodies of literature is in the often overlooked defining features of megalopolitan forms - their being the 'hub' that links national to international urban systems and the 'incubator' within national urban systems (Gottmann, 1976). With this intersection in mind, this paper measures the functional polycentricity of China's Yangtze River Delta Region (YRDR) at different geographical scales from an intercity knowledge collaboration perspective. The paper uses data on co-publications as an indicator of knowledge linkages between cities within and beyond this megalopolis. The YRDR can be seen as functionally polycentric at the megapolitan scale but this functional polycentricity decreases with increases in the geographical scale at which interurban linkages are considered. Furthermore, a multi-scalar analysis of functional polycentricity helps identify the hub role of Shanghai. The results show that Shanghai's knowledge hub role is currently present at the national scale. It may take some time for Shanghai to become a knowledge hub at the global scale given its not-so-strong international links and relatively weak local links. The paper concludes with some suggestions for future research agendas.
\end{abstract}

\section{Keywords}

functional polycentricity, knowledge collaboration, megalopolis, urban networks, Yangtze River Delta Region 


\section{Introduction}

A paradigmatic shift from metaphors of 'hierarchy' to those of 'network' has been apparent in the study of city systems. At the global scale, the world cities literature reveals a complex and evolving network of relationships between cities (Liu et al., 2014; Taylor et al., 2002, 2014). At the regional scale, polycentric urban regions (PURs) have been seen as a new urban form emerging in the context of contemporary globalisation (Burger et al., 2014; Hall and Pain, 2006; Kloosterman and Musterd, 2001). Indeed, polycentric development and urban networks are central to narratives of EU spatial planning (Faludi, 2004).

Despite the growing interest in polycentricity and urban networks at the regional scale, there have been calls for conceptual clarification of polycentricity (Burger and Meijers, 2012; Kloosterman and Musterd, 2001; Lambregts, 2009). One of the most obvious scholarly concerns is the distinction between morphological and functional polycentricity. The former usually refers to the balanced distribution of size and territory between cities within an urban system whereas the latter often focuses on the balanced distribution of functional relationships between settlements within an urban network (Burger and Meijers, 2012; Burger et al., 2014).

The debate over the nature of polycentricity essentially manifests two different approaches to urban regions. According to Harrison and Hoyler (2015), the morphologically dominated approach is adopted by what they call the 'North American school of megaregionalists' who prioritise spatial form as their starting point, whereas the functionally dominated approach appears more influential among what they dub the 'European school of megaregionlists' who focus on less visible (or even invisible) megaregional functions. Despite this major difference, the foundations upon which the two approaches are constructed date back to the 1950s when Gottmann $(1957,1964)$ promoted megalopolis as a new urban form at that time. ${ }^{1}$ In what follows, we use the terms megalopolis and megapolitan interchangeably. ${ }^{2}$

The renewed interest in the functional polycentricity of urban regions in and of itself is insufficient, however, to truly do justice to the articulation of PURs at an international scale, while discussion of world city networks rarely concerns itself with their articulation with national urban systems. ${ }^{3}$ Megalopolitan regions are fascinating precisely because of the often overlooked but critical roles that Gottmann (1957, 1964, 1976) ascribed to them as the hubs or hinges, on the one hand, and incubators, on the other hand. ${ }^{4}$ Gottmann described megalopolis as a hinge, a hub (or gateway) connecting cities within and beyond megalopolitan areas and an incubator of new trends, knowledge and innovation:

all megalopolitan regions have been hinges in terms of trade, and cultural, technological and population exchanges between the countries they belonged to and the outside world they participated in ... To the characteristics of megalopolis as a hinge and a mosaic, must be added its function as an incubator. This function is a threat to habit and stability, because is introduces change ... However, it is their mix of functions and their great dynamism that have made the megalopolitan regions so important in the present world. (Gottmann, 1976: 110)

By looking back to Gottmann's identification of these two important functions of megalopolises, this paper seeks further consideration of urban functional polycentricity. First, we note that, in contrast to the great emphasis placed upon functional polycentricity within megapolitan areas, relatively few studies have focused on the hinge, hub or gateway function of a megalopolis as 
connecting its constituent cities with the rest of the world. The hub function presents a picture of PURs, megalopolitan regions, unbound; placing them at the junction of national and international urban systems. Second, we suggest that, despite various types of inter-city linkages being explored in analysis of functional polycentricity, relatively little is known about the role of knowledge and knowledge collaboration in driving the formation of urban networks within and beyond megapolitan areas; this despite the connections to be made between the literature on 'buzz in global pipelines' (Bathelt et al., 2004) and relational economic geographies of knowledge (Bathelt and Glückler, 2011; Bathelt and Li, 2014). That is, the incubator role that may be present within PURs is underplayed. This paper therefore focuses on the two neglected functions of megalopolises from an intercity knowledge collaboration perspective. The major aim is to explore knowledge collaboration as a type of functional linkage connecting cities within and beyond megalopolises when measuring functional polycentricity of urban networks at different geographical scales.

\section{Linking functional polycentricity with knowledge collaboration}

\section{Functional polycentricity at different geographical scales}

The focus of contemporary debates on the functional polycentricity of urban networks has been concentrated on megapolitan areas. This can be seen from various connections between the word 'polycentric' and such territorial concepts as 'metropolitan region', 'urban region' and 'mega-city region' (Dieleman and Faludi, 1998; Hall and Pain, 2006; Kloosterman and Musterd, 2001). In general terms, a polycentric urban region is an urban network within which cities are geographically separated but functionally integrated. However, the degree of functional polycentricity should be scalable, as 'polycentricity at one scale may be monocentricity at another' (Nadin and Dühr, 2005: 82).

Despite the resurgence of interest in questions of functional polycentricity, little attention has focused on the comparison of functional polycentricity at different spatial scales - most studies focusing merely on the megapolitan scale (Burger and Meijers, 2012; Burger et al., 2014; De Goei et al., 2010). Notable exceptions are the studies of Hall and Pain (2006) and Taylor et al. (2008) on eight European polycentric mega-city regions. By applying the interlocking network model to mega-city regions, they measure the degrees of functional polycentricity of these regions at the regional, national and global scales. In their studies, each of them has measured polycentricity at three different geographical scales. Following a similar approach, Tang and $\mathrm{Li}$ (2014) calculate the degrees of functional polycentricity of China's Yangtze River Delta Region (YRDR) and Middle Yangtze Region also at the regional, national and global scales. A common conclusion of these studies is that the higher the geographical scale at which functional polycentricity is measured, the less functionally polycentric the region is.

Note, however, that empirical studies on the scale-dependent nature of functional polycentricity have been built predominantly upon evidence relating to intra- and interfirm linkages. This is mainly because advanced producer service (APS) firms can be connected with their subsidiaries at different geographical scales in an era of globalisation, whereas other kinds of linkages such as commuting trips are usually confined to the megapolitan scale. In this sense, one should bear in mind that whether the degree of functional polycentricity can be compared at different geographical scales depends on the types of function being analysed.

For certain types of function (e.g. economic or transportation functions) that can 
be examined at different geographical scales, analysing the multi-scalar nature of functional polycentricity is not just about measuring its degrees across different spatial scales; it is more or less predictable that the degree of functional polycentricity would decrease as the spatial scale increases. What makes the analysis of functional polycentricity at different geographical scales so important is that it enables us to investigate the position of cities within and beyond an urban network.

Although the debate on the positioning of cities is usually neglected in the literature of functional polycentricity, the positon of cities within an urban network has already been discussed by some works. Nijman (1996) distinguishes the different roles played by Miami in the US urban system and the global city system. He finds that the city is less important in terms of its position in the US urban hierarchy but it acts as a 'gateway' city connecting Central America to a wider world. Miami's gateway function at the global scale and relatively weak position at the national scale is also confirmed by Brown et al. (2002) who place Miami in the context of the world city network. Miami might be exceptional but its position highlights the importance of positioning cities within and beyond regional urban networks. Neal's (2011) classification of three urban types based on the difference between cities' size-based positionality and networkbased positionality also touches upon the relationship between cities and urban networks. However, the study does not distinguish network-based positionality at different geographical scales.

As the hinge, hub (Gottmann, 1964, 1976) or gateway function of a megalopolis is usually demonstrated through primary cities, it is important to examine the position of primary cities through the analysis of functional polycentricity at different geographical scales. Note that the functionality of primate cities within a megalopolis usually becomes more pronounced at higher geographical scales. Thus, there could be little functional difference between cities within a megalopolis if judged only by a relatively high degree of functional polycentricity at the megapolitan scale. However, such a conclusion could be misleading or partial since it downplays the roles of primate cities at the national and global scales. This could be the case for megalopolises under contemporary globalisation since it is this distinctive feature of being globally connected and locally disconnected, physically and socially, that makes mega-cities a new urban form' (Castells, 2000: 436).

\section{Knowledge collaboration as a type of intercity linkage within and beyond megalopolises}

Despite the incubator function of megalopolises being highlighted by Gottmann (1976), relatively few studies in functional urban networks literature have treated intercity knowledge collaboration as the linkage between cities most closely associated with this incubator function. Yet knowledge collaboration has become increasingly important in a globalising knowledge economy as individual cities as urban economic agglomerations are unlikely to be economically selfsustaining by reference solely or even largely to local sources of knowledge. Here, urban economic agglomeration is recast as a matter of 'buzz in global pipelines' (Bathelt et al., 2004) or as increasingly important cluster to cluster knowledge linkages (Bathelt and Li, 2014).

Most studies of urban networks at the megapolitan scale have relied upon relational data on firm linkages (Burger et al., 2014; Taylor et al., 2008), people flows (Burger and Meijers, 2012; Hall and Pain, 2006), information exchanges (Hall and Pain, 2006) and infrastructure connections 
(Liu et al., 2015). A detailed comparison of those types of functional linkages could be exhaustive and beyond the scope of this paper. However, it is still worth comparing knowledge collaboration with other types of functional linkages in some parts of the following discussion in order to justify the use of intercity knowledge collaboration as a type of functional linkage within and beyond megalopolises.

No matter which type of intercity linkage is concerned, cities do not automatically generate linkages between each other. It is the flows of people, goods, information, energy and money and the relationships established between people, firms and organisations that connect cities at different geographical scales. Intercity knowledge collaboration is generated through knowledge collaboration between their respective economic entities (e.g. people, firms and universities). By aggregating individual knowledge collaboration to the city level, one can then construct urban networks of knowledge collaboration between cities at different geographical scales.

While face-to-face contacts have traditionally been emphasised as the knowledge 'buzz' promoting agglomeration, the significance and desirability of measuring (Organization for Economic Co-operation and Development (OECD), 2005) knowledge collaboration by codified forms have also been recognised. In fact, original survey and secondary data-based approaches have been common in empirical studies on knowledge interactions, especially at the megapolitan scale. Whereas survey-based data have often been used to study the detailed geography of knowledge relating to individual or several cities (Shearmur and Doloreux, 2015; Simmie, 2003), analysis based on largescale secondary data on co-publications (Andersson et al., 2014; Hoekman et al., 2009; Ma et al., 2014) and co-patents (Ó huallacháin and Der-Shiuan, 2014; Wilhelmsson, 2009) have more commonly been used to describe interurban, interregional and even international knowledge networks.

The use of publications and patents as indicators of knowledge and innovation has its problems. Hoekman et al. (2009) argue that: (1) not all research leads to publications or patents; (2) the added value to knowledge of publications and patents varies; and (3) the number of publications and patents also vary among different disciplines and technological fields. However, they also acknowledge the value of using publications and patents to macro-scale studies of the geography of knowledge, given that they usually contain detailed information of researchers' addresses and data on publications and patents have become markedly more available and easy to access.

Recall that functional polycentricity should be analysed across different geographical scales when intercity linkages exist within and beyond megalopolises. Similar to the economic function (as reflected by firm linkages) of a megalopolis, intercity knowledge collaboration is also a type of function that can link cities at different geographical scales. However, knowledge collaboration has long been conceptualised as spatially bounded, which may partly explain the missing linkage between knowledge collaboration and megalopolises. It is not until recently that the trans-scalar nature of the geography of knowledge collaboration been widely discussed in the literature of economic geography with their units of analysis being firms (Simmie, 2003), cities (Ma et al., 2014) and regions (Hoekman et al., 2009). A major conclusion of these studies is that the geography of knowledge collaboration is not necessarily bound to the local scale. In most cases, national and global knowledge linkages are found to be as important as regional and local ones.

Given its trans-scalar nature, knowledge collaboration is arguably an ideal type of 
intercity functional linkage through which functional polycentricity of urban networks can be analysed at different geographical scales. Meanwhile, a megalopolis is arguably an ideal geographical scale at which both internal and external urban networks based upon intercity knowledge collaboration can be developed. While this observation appears straightforward, little attention has been placed on this kind of urban network. Notable exceptions that have touched upon the integration of intercity networks and knowledge collaboration are the studies of Matthiessen and Schwarz (2010), Andersson et al. (2014) and Ma et al. (2014) that quantify urban networks from the perspective of intercity knowledge collaboration. In their studies, intercity linkages are measured by the number of co-publications between cities. However, whereas the former study is conducted merely at the global scale, the latter two studies are conducted at the national scale (China). Given this research gap, an integrative framework of megapolitan urban networks and knowledge collaboration is thus required for a comprehensive understanding of the hinge, hub or gateway and the incubator functions of megalopolises in an era of globalisation.

\section{Research region and the methodology}

\section{The Yangtze River Delta Region}

So far studies on functional polycentricity have mainly focused on European megapolitan areas such as the Dutch Randstad (Burger and Meijers, 2012; Burger et al., 2014) and South East England (De Goei et al., 2010), relatively little is known about the polycentric development of megapolitan areas in China where the urbanisation process is peaking. Although polycentricity figures in China's numerous regional plans, whether those megapolitan areas are functionally coherent or are just politically defined as polycentric remains unclear.

The YRDR, historically and presently, is a key part of China's entire national economy. Gottmann (1976) included it as one of the world's six largest emerging megalopolises. Inspired by studies of world city network and PURs, some Chinese scholars have recently analysed the network structure of the YRDR (Tang and Li, 2014). However, these studies focus exclusively on the economic function (e.g. firm linkages) of this region and most of them just analyse functional polycentricity at the megapolitan scale.

According to the Yangtze River Delta Regional Planning promulgated by the Chinese central government in 2010, the YRDR is officially composed of three provinces (municipalities) with a total of 25 cities. There is also a narrowly defined delineation of the YRDR, which is known as the core area of this region (see Figure 1). This study adopts the official definition of the YRDR in case that some peripheral cities which may have strong knowledge links with core cities are excluded.

\section{Constructing urban networks of knowledge collaboration}

Co-publications and co-patents are two common indicators for the measurement of knowledge collaboration. Here, we focus only on the use of co-publications. ${ }^{5}$ Each publication contains highly detailed information of researcher's name and address upon which one can build intercity knowledge collaboration networks by aggregating individual knowledge collaboration to the city level.

There are basically two kinds of counting methods to aggregate the times of connectivity between two cities. One is 'full counting', which means each co-occurrence of a pair of cities in one publication is counted as 1 . The 




Figure I. The Yangtze River Delta Region.

other is 'fractional counting' which means each co-occurrence of a pair of cities is divided by the total number of city pairs. Since some studies have demonstrated that both methods yield very similar results
(Hoekman et al., 2009), this study adopts the full counting approach. The network connectivity of cities can be derived from the connectivity matrix by employing the following expression 


$$
C_{i}=\sum_{j}^{n} C_{i j}(i \neq j)
$$

where $C_{i}$ is the connectivity of city $i$ in intercity networks, $C_{i j}$ is the interaction between city $i$ and $j$ which is represented by the number of co-publications between the two cities. $^{6}$

Data on co-publications are retrieved from Web of Science Core Collection Database, which is the most widely used electronic archive of international publications. Note that we do not use Chinese domestic databases. Although they obviously contain more papers co-authored by people living in different cities within the YRDR and China as a whole, Chinese domestic databases rarely include papers written through international collaboration, which in the main are published in English and included only by databases such as Web of Science. It might be argued that Chinese domestic databases can be used to measure intercity knowledge collaboration at the megapolitan and national scales while Web of Science can be used to measure such collaboration at the global scale. However, there are problems in the uniformity of data quality. It is generally acknowledged that being published in Web of Science is on average more difficult than for Chinese domestic databases. On the one hand, the number of co-publications in the former could be substantially smaller than in the latter. Yet, on the other hand, the higher the quality of publications, the greater the likelihood of genuine interactions between co-authors. In any case, the database used in this paper contains a sufficiently large number of articles co-authored at the megapolitan and national scales to offer the sort of multiscalar perspective advocated in this paper. To smooth fluctuation in the number of copublications, data were collected from 2012 to 2014. This alone is a time-consuming process but provides us with a total number of nearly 190,000 observations (articles only). After that, we calculate their average value as the number of co-publications between each pair of cities.

The lists of cities with which cities within the YRDR may have knowledge collaboration at the national and global scales are selected separately. At the national scale, 39 cities are selected based on the criterion that each city has more than 500 publications in 2014. Although this is an arbitrary cut-off value, almost all the provincial capital cities, municipalities and other major cities of China are included under this criterion. Moreover, almost all cities in this list also appear in other studies on China's intercity knowledge collaboration (Ma et al., 2014), supporting the reliability of the cities selected in this study. At the global scale, the world cities selected by Taylor et al. (2002) are an ideal choice since most of them are also knowledge centres. ${ }^{7}$ However, some cities such as Cambridge and Oxford, which produce a vast number of publications, are not included. Hence, this catalogue is supplemented with Matthiessen and Schwarz's (2010) list of top 30 world knowledge centres. The end result is a list of 133 world cities.

\section{Measuring the degree of functional polycentricity}

Approaches to quantifying functional polycentricity can be mainly classified into three groups: (1) the regression method based on rank-size distribution of functional linkages; (2) the network method drawn from social network analysis; and (3) the modelling method comparing the observed functional polycentricity with theoretically 'perfect' polycentricity (c.f. Liu et al., 2015).

This study follows the regression method widely used in the literature (Burger et al., 2014; Meijers, 2008). The distribution of cities' total linkages is realised using the ranksize distribution. The major indicator is the 
slope of the best-fitting regression line which ranges from 0 (completely functional polycentric) to $-\infty$ (completely functional monocentric) (Meijers, 2008). However, this method is not unproblematic. A critical question concerns the sample size of cities in the distribution as it strongly influences the slope of the regression line. Generally, the sample size can be determined by a fixed number of cities, a given size threshold or a certain proportion of the total number of cities. Meijers (2008) distinguishes these approaches and argues that a fixed number of cities could be the best choice when measuring functional polycentricity. In order to smooth fluctuation, some studies calculate the average value of the slopes of different sample sizes of cites (Burger and Meijers, 2012).

\section{Knowledge collaboration within and beyond the Yangtze River Delta Region: Results of a multi- scalar analysis}

\section{Intercity linkages within and beyond the YRDR}

Figure 2 shows knowledge networks within and beyond the YRDR. Given space constraints, only intercity links with 200 co-publications or more are shown in the figure. Several conclusions can be drawn. First, the trans-scalar nature of the geography of knowledge collaboration is supported in this study. It is obvious to see that intercity knowledge links exist not only between cities within the YRDR but also between cities from the region and cities at the national and global scales. Recall that the transscalar geography of knowledge collaboration is the prerequisite for measurement of the degrees of functional polycentricity at different geographical scales.

Second, the knowledge network structure at the megapolitan scale conforms to the widely held recognition of the spatial structure of the YRDR from the perspective of economic development. Knowledge collaboration between the three largest cities (Shanghai, Nanjing and Hangzhou) dominates over other intercity links at the megapolitan scale. Meanwhile, the three largest cities also have relatively strong links with other smaller cities of the region. According to Andersson et al. (2014), it can be inferred that smaller cities tend to pursue economic development and upgrade their positions in urban networks through the lens of seeking knowledge collaboration with larger cities which have easy accesses to funds and research resources.

Third, the distribution pattern of knowledge links at the megapolitan and national scales is in line with the study of Andersson et al. (2014) which finds the geography of Chinese science is spatially and politically biased and has the same-province effect. On the one hand, almost all strong knowledge links exist between capital cities and municipalities directly under the central government. On the other hand, six of the nine intercity links at the megapolitan scale are intra-provincial (the other three links are between Shanghai, Nanjing and Hangzhou).

Fourth, the strength of intercity links at the megapolitan scale is on average weaker than the strength of those at the national scale but stronger than the strength of those at the global scale. This is mainly because there are a number of capital cities outside the YRDR which have strong knowledge collaboration with the region's three largest cities, whereas cities at the global scale only have relatively weak knowledge collaboration with Shanghai.

\section{Knowledge links at different geographical scales}

Table 1 lists the top five cities in terms of their total knowledge links which will be used to measure the degree of functional 


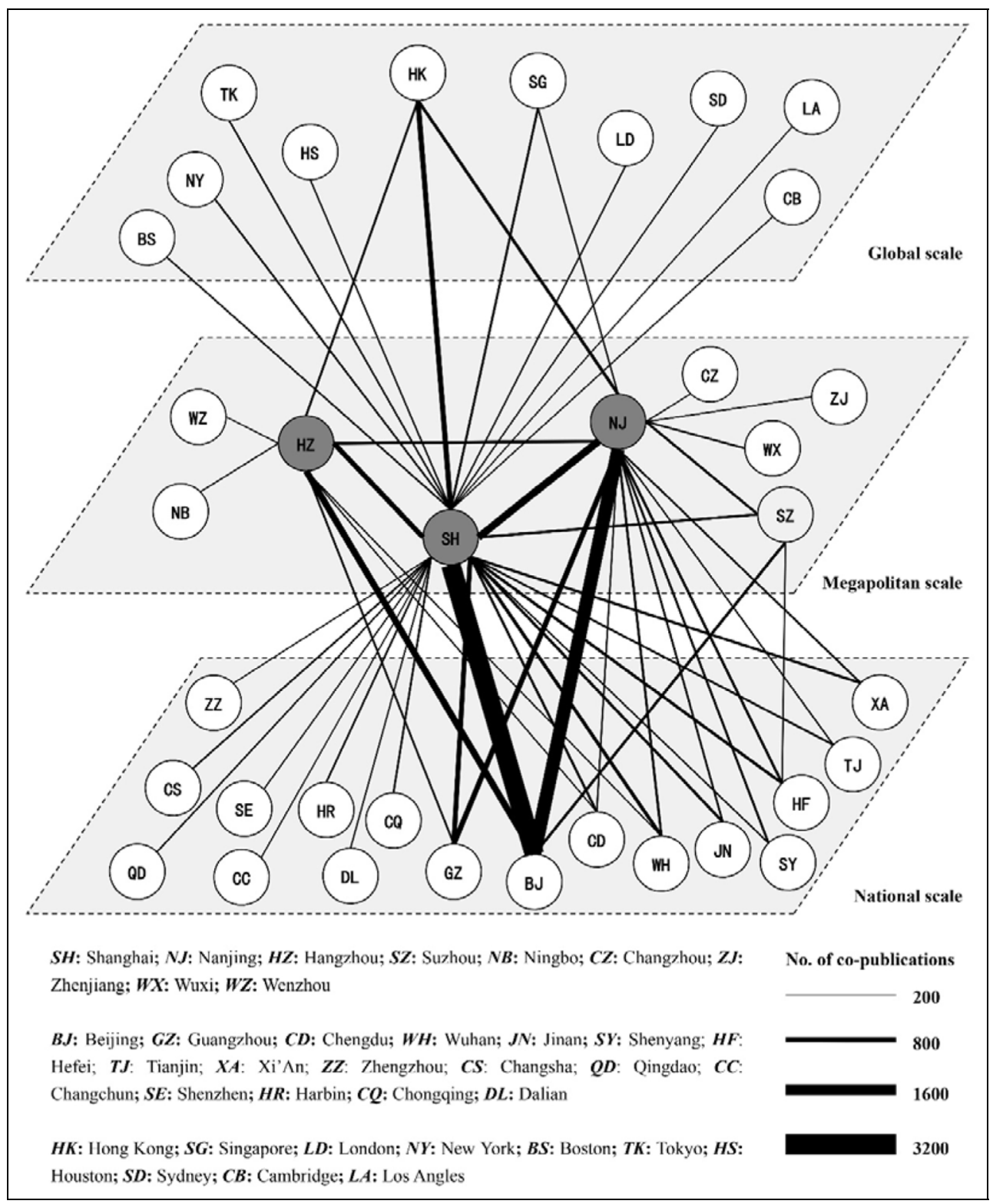

Figure 2. Knowledge networks within and beyond the YRDR (only links with 200 co-publications or more are shown).

Note: Although Beijing, Guangzhou and Hong Kong are all on the list of world cities, we treat the former two as cities at the national scale and the latter as a city at the global scale by taking account of their different roles in China's national urban system.

polycentricity. The total knowledge links of each city are calculated based on equation
(1). Two major findings need to be highlighted here. 
Table I. Top five cities in terms of knowledge links at different geographical scales.

\begin{tabular}{|c|c|c|c|c|c|c|}
\hline \multirow[t]{2}{*}{ Rank } & \multicolumn{2}{|c|}{ Megapolitan scale } & \multicolumn{2}{|c|}{ National scale } & \multicolumn{2}{|c|}{ Global scale } \\
\hline & City & Links & City & Links & City & Links \\
\hline I & Nanjing & 3812 & Shanghai & 10,287 & Shanghai & 9289 \\
\hline 2 & Shanghai & 3669 & Nanjing & 7629 & Nanjing & 8308 \\
\hline 3 & Hangzhou & 2357 & Hangzhou & 4100 & Hangzhou & 2154 \\
\hline 4 & Suzhou & 1342 & Suzhou & 1888 & Suzhou & 847 \\
\hline 5 & Wuxi & 773 & Ningbo & 667 & Xuzhou & 219 \\
\hline
\end{tabular}

First, Nanjing more than matches Shanghai as the city with the largest knowledge links at the megapolitan scale. ${ }^{8}$ This finding can be expected if we look back to Figure 2 which shows that Nanjing maintains the largest number of strong knowledge links with cities within the YRDR. However, this is also to some extent unexpected, given Shanghai's dominating position in the region. The finding is also different from the study of Tang and Li (2014), which finds Shanghai has the largest economic links with other cities (measured by intra-firm linkages) at the megapolitan scale. Several possible explanations could be explored here. The first relates to the above-mentioned spatial political bias and same-province effect of the geography of Chinese science (Andersson et al., 2014). In China, it is easy for particular provincial authorities and institutions to encourage intercity knowledge collaboration within the province, whereas interprovincial knowledge collaboration is often confronted with difficulties such as co-application of research projects, share of research resources and allocation of research funds. As the capital of Jiangsu province, Nanjing is undoubtedly an ideal city with which other cities from the same province seek to develop knowledge collaboration. Another reason is that Nanjing has a number of nationally renowned universities and research institutes. This helps explain why Hangzhou, the capital of Zhejiang province, has a relatively small number of knowledge links since it has a very limited number of universities and research institutes. The third reason relates to the strategies of cities' scientific development. Like small cities that seek knowledge collaboration with large cities of the YRDR, universities and research institutes in Shanghai would be more willing to collaborate with those from other major Chinese cities such as Beijing and Guangzhou and from other countries. This also helps explain the dominating role of Shanghai at the national and global scales.

Second, there are subtle changes in the composition of the top five cities. Obviously, Shanghai, Nanjing, Hangzhou and Suzhou are constantly included in the list. However, the fifth city is different at different geographical scales. This indicates that some nonprimate cities may be more able to develop knowledge collaboration with cities at a certain geographical scale. For instance, although Xuzhou is found to be among the top five cities at the global scale, it has relatively small knowledge links at the megapolitan and national scales, only ranking 11 th and $7^{\text {th }}$, respectively.

\section{The degree of functional polycentricity at different geographical scales}

By adopting the rank-size distribution method, we plotted cities' total knowledge links against their ranks. In line with Burger 
Table 2. Degrees of functional polycentricity at different geographical scales.

\begin{tabular}{llll}
\hline Sample size & Megapolitan scale & National scale & Global scale \\
\hline Size $=3$ & -0.396 & -0.794 & -1.211 \\
Size $=4$ & -0.701 & -1.156 & -1.712 \\
Size $=5$ & -0.957 & -1.585 & -2.262 \\
Average & -0.685 & -1.178 & -1.728 \\
\hline
\end{tabular}

and Meijers (2012), we measured the degrees of functional polycentricity based on different sample sizes (3, 4 and 5) of cities and then calculated the average value of these slopes as the final degree of functional polycentricity (see Table 2). Recall that the smaller the scores of the slopes, the less functional polycentric the megalopolis. As we can see, the degree of functional polycentricity decreases as the sample size increases. Moreover, the higher the geographical scale examined, the less functionally polycentric the YRDR. This means that the YRDR tends to become less functionally polycentric at a higher geographical scale. The finding is consistent with other studies that examine the multi-scalar nature of functional polycentricity from intercity economic linkages (Hall and Pain, 2006; Tang and Li, 2014; Taylor et al., 2008). This implies that the knowledge function at different geographical scales is distributed in the same way as the economic function of a megalopolis.

\section{The gateway role of the YRDR: At which geographical scale?}

Recall that the multi-scalar analysis of functional polycentricity can shed some light on the hub or gateway function of a megalopolis. However, most studies that have analysed functional polycentricity at different geographical scales have placed less attention on making the connections from the results of analysis to considerations of a megalopolis' gateway role. Since the hub or gateway role of a megapolis is generally represented by its primate city, it is worth reconsidering the gateway role played by Shanghai in connecting the YRDR with the rest of the world from the perspective of its knowledge function.

It has been reported that Shanghai has set up the new vision of becoming a global city by 2040, which will be stated in its new Master Plan. ${ }^{9}$ The aspiration for Shanghai to be a global city underlines its likely future function as a hub or gateway city linking cities within and beyond the YRDR. We are unable to examine the extent to which Shanghai has fulfilled its gateway role in terms of its economic, financial, trade and shipping functions through this study. However, judging by its knowledge function at different geographical scales, it is clear that Shanghai is on its way to becoming a knowledge gateway of the YRDR, both nationally and internationally.

The above results of the multi-scalar analysis of functional polycentricity have already suggested that Shanghai has more external knowledge links than other YRDR cities at the national and global scales (see Figure 2, Tables 1 and 2). Table 3 provides a closer inspection of Shanghai's gateway role by listing the top 40 cities that have the largest knowledge links with Shanghai. As we can see, the external knowledge links of Shanghai are mainly concentrated at the national scale, followed by the global scale and relatively weak links at the megapolitan scale. This conforms to an argument that:

centers at the top of the urban hierarchy in an urban system are disproportionally connected 
Table 3. Top 40 cities that have the largest knowledge links with Shanghai.

\begin{tabular}{llllllll}
\hline Rank & City & Rank & City & Rank & City & Rank & City \\
\hline 1 & Beijing & 11 & Chengdu & 21 & Shenyang & 31 & Taipei \\
2 & Nanjing & 12 & Singapore & 22 & Houston & 32 & Paris \\
3 & Hong Kong & 13 & Tianjin & 23 & London & 33 & Wuxi \\
4 & Hangzhou & 14 & New York & 24 & Dalian & 34 & Lanzhou \\
5 & Guangzhou & 15 & Chongqing & 25 & Sydney & 35 & Nanchang \\
6 & Wuhan & 16 & Changsha & 26 & Cambridge & 36 & Chicago \\
7 & Hefei & 17 & Harbin & 27 & Shenzhen & 37 & Fuzhou \\
8 & Jinan & 18 & Boston & 28 & Zhengzhou & 38 & Philadelphia \\
9 & Xi'An & 19 & Tokyo & 29 & Changchun & 39 & Wenzhou \\
10 & Suzhou & 20 & Qingdao & 30 & Los Angeles & 40 & Kunming \\
\hline
\end{tabular}

Note: Cities at different geographical scales are indicated by font style: cities within the YRDR are in bold, cities at the national scale are in roman font and cities at the global scale are in italic.

to this 'outside world' because of better accessibility and the higher-order functions they provide. Indeed, some centers fulfil a global or national function, while other centers fulfil a more regional or local function. (Burger and Meijers, 2012: 1132)

However, it should be noted that Shanghai's global reach in terms of knowledge links is not as strong as its national reach, which means that Shanghai may still have a long way to go before fully shouldering the burden of gateway function for the YRDR. Meanwhile, Shanghai should also strengthen its knowledge links with cities within the YRDR. At present, Shanghai's knowledge links with other local cities are relatively weak, except from those with Nanjing and Hangzhou, the two subcentres of the YRDR. However, a gateway city of a megalopolis should be a city that not only has a strong global reach but also has the ability to connect the global with the local. Otherwise, it will function just as the sort of mega-city described by Castells (2000) as 'globally connected and locally disconnected'.

\section{Conclusion}

This study builds upon recent interest in functional polycentricity, which highlights a balanced distribution of functional linkages between cities within an urban network. In contrast to most studies that have focused exclusively on economic and commuting functions of a polycentric urban region and measured functional polycentricity at a certain geographical scale (Burger and Meijers, 2012; De Goei et al., 2010), this study examines the concept of functional urban polycentricity from an intercity knowledge collaboration perspective through the lens of the comparison of functional polycentricity at different geographical scales. In doing so, we reinstate the importance of the 'hinge' and 'incubator' functions of a megalopolis noted by Gottmann (1976) 40 years ago.

An appreciation of these rather neglected functions of megapolitan areas also has the happy side-effect of encouraging dialogue between bodies of literature that have remained only weakly connected. Whereas typically the literature on world cities, 'buzz in global pipelines' emphasises the global connections of, and hub role performed by, certain cities, the literature on PURs typically has emphasised the incubator and local (national or intra-national) redistributive role performed by systems of cities. A return to these two key defining features of megalopolis alerts us to the fact that functionally 
PURs contain within them the seeds of both. $^{10}$

The use of intercity knowledge linkages is suitable for the case of China where the concept of PURs has also gained in popularity as indicated by the proliferation of regional plans making reference to notions of polycentricity or otherwise addressing polycentric urban regions. Owing to the unavailability of detailed data on commuting trips between cities, most studies on China's PURs have relied upon data on intra-APS firm linkages and been conducted at the megapolitan scale. In contrast, intercity knowledge collaboration not only offers a new perspective but also enables us to examine the concept of functional polycentricity at different geographical scales.

The empirical results based on the case of the YRDR also confirm the reliability of the use of intercity knowledge linkages. In line with studies that have analysed the multiscalar nature of functional polycentricity (Hall and Pain, 2006; Tang and Li, 2014; Taylor et al., 2008), this study also finds a decreasing degree of functional polycentricity as the geographical scale increases. Moreover, this finding leads us to reflect on the gateway role of Shanghai in terms of its knowledge function in connecting the global with the local. There is strong evidence for Shanghai's knowledge gateway role at the national scale but it may take some time for Shanghai to become a knowledge gateway of the YRDR at the global scale.

The current study has its limitations which serve as departure points for future research. First, co-publications are just one indicator for intercity knowledge linkages and thus can only provide a partial understanding of knowledge collaboration between cities within and beyond a megalopolis. Future analysis could also examine the patterns revealed in co-patent data. Second, databases on co-publications usually contain publishing information over a long period which enables a longitudinal analysis of the evolution of functional polycentricity of a given megalopolis. Recent studies on the world city network have begun to focus on shifts in the structure of the network over time (Liu et al., 2014). Some studies on PURs have also touched upon the evolution of urban networks (De Goei et al., 2010). Third, mechanisms behind the formation of urban networks based on intercity knowledge collaboration remain to be explored. An econometric analysis may be required to answer questions as to why certain pairs of cities have more knowledge links than others. Fourth, a comparative study may be needed to examine whether China's other megapolitan areas share the same patterns and processes of being functionally polycentric as the YRDR or have their own characteristics and trajectories. This last aspect also leads on to questions regarding the agglomeration economies generated by the functional polycentricity of urban networks - questions raised by Phelps and Ozawa (2003) and Burger et al. (2014). A recent study by Meijers et al. (2016) examined the relationship between network connectivity and metropolitan functions in Europe. In terms of knowledge function, it is natural to ask whether a city with higher network connectivity would be more productive in its reception, generation and dissemination of knowledge and if so which geographical scale matters most?

\section{Acknowledgement}

The authors would also like to thank the editor and three anonymous referees for their very helpful and constructive comments. However, the authors take sole responsibility for their views.

\section{Funding}

Funding was received from the China Scholarship Council, No.: 201406090167. 


\section{Notes}

1. Morphology was emphasised in the original conception of megalopolis by Geddes (1915) and Mumford (1938). Gottmann also touched on the functional aspect of megalopolises, which is often neglected in today's reading of his work (Lang and Knox, 2009).

2. Nelson and Lang (2011) eschew Gottmann's (1964) fixed population threshold for megalopolis in favour of a definition based on the coalescence of 23 megapolitan areas (composed of at least one metropolitan area with an expected population of at least 2 million in 2040 and connected by through labour market or transport flows to at least one another metropolitan area of at least 250,000 population in 2040) into ten US megapolitan clusters.

3. There are two notable exceptions that have touched upon the relationship between world city networks and national urban systems (see Ma and Timberlake, 2013; Taylor and Derudder, 2016).

4. In this paper we use the terms hub, hinge and gateway interchangeably since Gottmann (1964, 1976) used the first two while the latter is a more accessible term to depict the functional role of some cities in articulating national and international urban systems.

5. Neither co-publications nor co-patents can present a full picture of knowledge collaboration. While patents are commonly believed to be market driven, Andersson et al. (2014) find that there is spatial political bias in intercity co-publications. This provides one argument in favour of analysing urban networks based on co-publications in the current Chinese urban system. A second argument in favour is based on the fact that the number of co-publications between cities is substantially larger than that of co-patents - inclusion of co-patents in our analysis would have a trivial effect on network structures. The comparison of the two indicators is beyond the scope of this paper.

6. Some studies use relative (greater-thanexpected) figures to reflect strong intercity knowledge links (e.g. Andersson et al., 2014).
However, we need to rely upon absolute figures to represent knowledge links that have really existed between cities. This is also in line with other urban network studies (e.g. Burger and Meijers, 2012; Taylor et al., 2008).

7. The number of world cities selected by GaWC's study has expanded significantly to 526 included in a recent study (Taylor et al., 2014). It is excessively time-consuming to search co-publications between YRDR cities and all world cities. Even in the list of 133 cities selected for this study, we found limited number of co-publications between the YRDR and world cities. The 133 used here cover most of the world cities with knowledge collaboration with YRDR cities.

8. This is not a coincidence. In fact, we find that Nanjing has ranked the first in term of its knowledge links at the megapolitan scale since 2012.

9. See http://usa.chinadaily.com.cn/epaper/ 2014-06/27/content_17619764.htm (accessed 8 November 2015).

10. While the interconnections between national and regional innovations systems are apparent in the extant literature, it may also be the case that questions of the articulation between regional and national innovation systems and the international or global innovation system architecture have been insufficiently explored.

\section{References}

Andersson DE, Gunessee S and Matthiessen CW (2014) The geography of Chinese science. Environment and Planning A 46(12): 2950-2971.

Bathelt H and Glückler J (2011) The Relational Economy: Geographies of Knowing and Learning. Oxford: Oxford University Press.

Bathelt H and Li PF (2014) Global cluster networks: Foreign direct investment flows from Canada to China. Journal of Economic Geography 14: 45-71.

Bathelt H, Malmberg A and Maskell P (2004) Clusters and knowledge: Local buzz, global pipelines and the process of knowledge creation. Progress in Human Geography 28(1): $31-56$. 
Brown E, Taylor PJ and Catalano G (2002) Beyond world cities: Central America in a global space of flows. Area 34(2): 139-148.

Burger MJ and Meijers E (2012) Form follows function? Linking morphological and functional polycentricity. Urban Studies 49(5): 1127-1149.

Burger MJ, Meijers EJ and Van Oort FG (2014) Editorial: The development and functioning of regional urban systems. Regional Studies 48(12): 1921-1925.

Burger MJ, Van der Knaap B and Wall RS (2014) Polycentricity and the multiplexity of urban networks. European Planning Studies 22(4): 816-840.

Castells M (2000) The Information Age: Economy, Society and Culture. Vol. 1, The Rise of the Network Society. Oxford: Blackwell.

De Goei B, Burger MJ, Van Oort FG, et al. (2010) Functional polycentrism and urban network development in the Greater South East, United Kingdom: Evidence from commuting patterns, 1981-2001. Regional Studies 44(9): 1149-1170.

Dieleman FM and Faludi A (1998) Polynucleated metropolitan regions in Northwest Europe: Theme of the special issue. European Planning Studies 6(4): 365-377.

Faludi A (2004) Spatial planning traditions in Europe: Their role in the ESDP process. International Planning Studies 9(2-3): 155-172.

Geddes SP (1915) Cities in Evolution: An Introduction to the Town Planning Movement and to the Study of Civics. London: Williams \& Norgate.

Gottmann J (1957) Megalopolis or the urbanization of the northeastern seaboard. Economic Geography 33(3): 189-200.

Gottmann J (1964) Megalopolis: The Urbanized Northeastern Seaboard of the United States. Cambridge, MA: MIT Press.

Gottmann J (1976) Megalopolitan systems around the world. Ekistics 243(2): 109-113.

Hall PG and Pain K (2006) The Polycentric Metropolis: Learning from Mega-city Regions in Europe. London: Routledge.

Harrison J and Hoyler M (eds) (2015) Megaregions: Globalization's New Urban Form? Cheltenham: Edward Elgar Publishing.

Hoekman J, Frenken K and van Oort F (2009) The geography of collaborative knowledge production in Europe. The Annals of Regional Science 43(3): 721-738.

Kloosterman RC and Musterd S (2001) The polycentric urban region: Towards a research agenda. Urban Studies 38(4): 623-633.

Lambregts B (2009) The Polycentric Metropolis Unpacked: Concepts, Trends, and Policy in the Randstad Holland. Amsterdam Institute for Metropolitan and International Development Studies, Amsterdam.

Lang R and Knox PK (2009) The new metropolis: Rethinking megalopolis. Regional Studies 43(6): 789-802.

Liu XJ, Derudder B and Taylor PJ (2014) Mapping the evolution of hierarchical and regional tendencies in the world city network, 20002010. Computers, Environment and Urban Systems 43: 51-66.

Liu XJ, Derudder B and Wu K (2015) Measuring polycentric urban development in China: An intercity transportation network perspective. Regional Studies 50(8): 1302-1315.

Ma H, Fang C, Pang B, et al. (2014) The effect of geographical proximity on scientific cooperation among Chinese cities from 1990 to 2010. PloS One 9(11): e111705.

Ma X and Timberlake M (2013) World city typologies and national city system deterritorialisation: USA, China and Japan. Urban Studies 50(2): 255-275.

Matthiessen CW and Schwarz AW (2010) World cities of scientific knowledge: Systems, networks and potential dynamics: an analysis based on bibliometric indicators. Urban Studies 47(9): 1879-1897.

Meijers EJ (2008) Measuring polycentricity and its promises. European Planning Studies 16(9): 1313-1323.

Meijers EJ, Burger MJ and Hoogerbrugge MM (2016) Borrowing size in networks of cities: City size, network connectivity and metropolitan functions in Europe. Papers in Regional Science 95(1): 181-198.

Mumford L (1938) The Culture of Cities. New York: Harcourt, Brace \& World.

Nadin V and Dühr S (2005) Some help with Euro-planning jargon. Town and Country Planning 74(3): 82. 
Neal ZP (2011) From central places to network bases: A transition in the US urban hierarchy, 1900-2000. City \& Community 10(1): 49-75.

Nelson AC and Lang R (2011) Megapolitan America: A new Vision for Understanding America's Metropolitan Geography. Chicago IL: American Planning Association.

Nijman J (1996) Breaking the rules: Miami in the urban hierarchy. Urban Geography 17(1): 5-22.

Ó huallacháin B and Der-Shiuan L (2014) Urban centers and networks of co-invention in American biotechnology. The Annals of Regional Science 52(3): 799-823.

Organization for Economic Co-operation and Development (2005) Oslo Manual: The Measurement of Scientific and Technological Activities. Paris: OECD.

Phelps NA and Ozawa T (2003) Contrasts in agglomeration: Proto-industrial, industrial and post-industrial forms compared. Progress in Human Geography 27(5): 583-604.

Shearmur R and Doloreux D (2015) Central places or networks? Paradigms, metaphors, and spatial configurations of innovationrelated service use. Environment and Planning A 47(7): 1521-1539.
Simmie J (2003) Innovation and urban regions as national and international nodes for the transfer and sharing of knowledge. Regional Studies 37(6-7): 607-620.

Tang ZL and Li T (2014) A comparative analysis of urban systems in the Yangtze Delta Region and the Middle Yangtze Region: An approach of firm-based interlocking network. Urban Planning Forum 2014(2): 24-31 [in Chinese].

Taylor PJ and Derudder B (2016) World City Network: A Global Urban Analysis. London: Routledge.

Taylor PJ, Catalano G and Walker DR (2002) Exploratory analysis of the world city network. Urban Studies 39(13): 2377-2394.

Taylor PJ, Derudder B, Hoyler M, et al. (2014) City-dyad analyses of China's integration into the world city network. Urban Studies 51(5): 868-882.

Taylor PJ, Evans DM and Pain K (2008) Application of the interlocking network model to mega-city-regions: Measuring polycentricity within and beyond city-regions. Regional Studies 42(8): 1079-1093.

Wilhelmsson M (2009) The spatial distribution of inventor networks. The Annals of Regional Science 43(3): 645-668.

Appendix I. The list of cities at the national scale that are used to calculate knowledge links with cities within the YRDR.

\begin{tabular}{llll}
\hline Beijing & Hefei & Fuzhou & Qinhuangdao \\
\hline Guangzhou & Chongqing & Nanchang & Hohhot \\
Wuhan & Shenyang & Taiyuan & Luoyang \\
Xi'An & Dalian & Shijiazhuang & Haikou \\
Chengdu & Qingdao & Nanning & Kaifeng \\
Tianjin & Lanzhou & Urumqi & Daqing \\
Changsha & Shenzhen & Baoding & Weihai \\
Jinan & Kunming & Yantai & Tangshan \\
Harbin & Zhengzhou & Guiyang & Dongguan \\
Changchun & Xiamen & Guilin & \\
\hline
\end{tabular}

